\title{
Thermoelectric Microconverter for Energy Harvesting Systems
}

\author{
João Paulo Carmo, Member, IEEE, Luis Miguel Gonçalves, and José Higino Correia, Member, IEEE
}

\begin{abstract}
This paper presents a solution for energy microgeneration through energy harvesting by taking advantage of temperature differences that are converted into electrical energy using the Seebeck effect. A thermoelectric microconverter for energy scavenging systems that can supply low-power electronics was fabricated using thin films of bismuth and antimony tellurides. Thin films of n-type bismuth $\left(\mathrm{Bi}_{2} \mathrm{Te}_{3}\right)$ and p-type antimony $\left(\mathrm{Sb}_{2} \mathrm{Te}_{3}\right)$ tellurides were obtained by thermal coevaporation with thermoelectric figures of merit $(Z T)$ at room temperature of 0.84 and 0.5 and power factors $\left(P F \times 10^{-3}\left[\mathrm{~W} \cdot \mathrm{K}^{-1} \cdot \mathrm{m}^{-2}\right]\right)$ of 4.87 and 2.81 , respectively. The films were patterned by photolithography and wet-etching techniques. The goal for this thermoelectric microconverter is to supply individual electroencephalogram (EEG) modules composed by an electrode, processing electronics, and an antenna, where the power consumption ranges from hundredths of microwatts to a few milliwatts. Moreover, these wireless EEG modules allow patients to maintain their mobility while simultaneously having their electrical brain activity monitored.
\end{abstract}

Index Terms-Energy harvesting, microgeneration, renewable energy sources, thermoelectric energy scavenging systems.

\section{INTRODUCTION}

C URRENTLY, there is an increased interest in renewable sources of power, particularly in applications that require high power levels [1]-[4]. There is also an increasing interest in ubiquitous electronic devices in everyday life. Moreover, the complexity and requirements of these devices do not know limits. The use of batteries cannot be enough to ensure an uninterruptible working cycle. Thus, the association of such devices with the use of some kind of energy-recovering system can reveal an interesting approach [5]. Energy scavengers are currently emerging for a number of applications from biomedical to automotive [4], [6]. Typically, one can distinguish between two types of energy scavengers, e.g., macroenergy scavengers that are typically in the cubic-centimeter range and microenergy scavengers that are typically in the cubic-millimeter range and manufactured using micromachining techniques. Microenergy scavengers are small electromechanical devices that harvest ambient energy and convert it into electricity [7]. Energy scavengers could harvest different types of energy. Solar energy can be harvested and stored by means of photovoltaic solar

Manuscript received February 20, 2009; revised October 7, 2009. First published October 20, 2009; current version published February 10, 2010. This work was supported by the Portuguese Foundation for Science and Technology FCT/PTDC/EEA-ENE/66855/2006 Project.

The authors are with the Department of Industrial Electronics, University of Minho, 4800-058 Guimarães, Portugal (e-mail: jcarmo@dei.uminho.pt; lgoncalves@dei.uminho.pt; higino.correia@dei.uminho.pt).

Color versions of one or more of the figures in this paper are available online at http://ieeexplore.ieee.org.

Digital Object Identifier 10.1109/TIE.2009.2034686

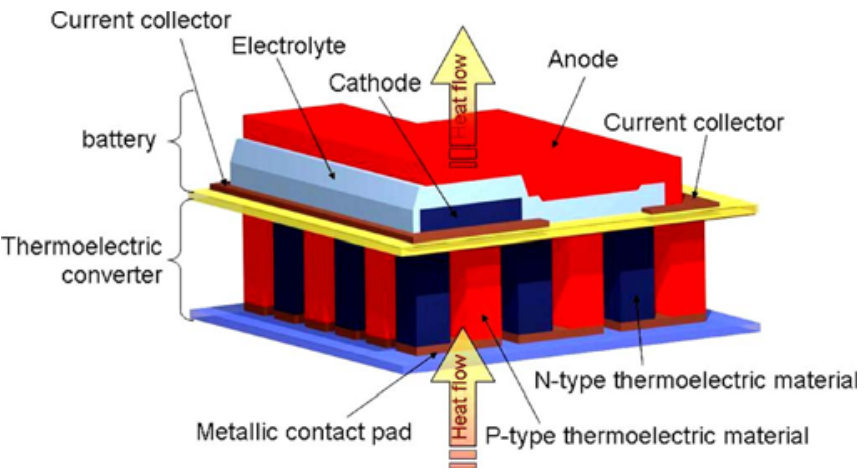

Fig. 1. Artwork of a thermoelectric microsystem. When the heat flows across the junction, an electrical power current is generated by the Seebeck effect. Practical thermoelectric generators connect a large number of junctions in series to increase the operating voltage.

cells with a charge-integrating capacitor for periods of darkness [8], mechanical energy can be harvested with piezoelectric or electrostatic converters [9], electromagnetic energy can be harvested through radio-frequency resonators [10], and, finally, thermal energy can be harvested with thermoelectric generators [11].

The majority of microenergy scavengers are still in the research and development phase. However, thermoelectric was the first one to appear on the market [7]. This was due to the easiness to fabricate these devices with solid-state technology and because they are based on a well-established physical theory. In 1822, Seebeck noticed that the needle of a magnet was deflected in the presence of dissimilar metals that were connected (electrically in series and thermally in parallel) and exposed to a temperature gradient [11], [12]. The effect observed is the basis for thermoelectric power generation. As shown in Fig. 1, if the junctions at the bottom are heated and those at the top are cooled (producing a temperature differential), electron/hole pairs will be created at the hot end and absorb heat in the process. The pairs recombine and reject heat at the cold edges. A voltage potential, the Seebeck voltage, which drives the hole/electron flow, is created by the temperature difference between the hot and cold edges of the thermoelectric elements. The net voltage appears across the bottom of the thermoelectric element legs.

The efficiency optimization of these converters needs thermoelectric materials that are simultaneously good electric conductors to minimize Joule heating and poor thermal conductors to retain the heat at the junction, and the Seebeck effect must be maximized in order to produce the required voltage [13]. A tradeoff exists when a simultaneous optimization of these three properties is pursued. The simple fact that the electrons 
carry unwanted heat, as well as electric current, will make the Seebeck effect decrease when the electrical conductivity increases. The highest performance is obtained in the presence of heavily doped semiconductors, such as bismuth telluride or silicon germanium. In the case of semiconductors, the most desirable situation is when the base materials are both $\mathrm{n}$ - and p-doped in order to apply the same material system on both sides of the junctions [12]. In addition, so that it will be integrated in silicon microsystems, a thermoelectric generator must be small in size, must be light in weight, and must have silicon compatibility. Thin-film generators are the most suited ones for microsystem applications because they give the advantage of obtaining modules with minimum size and weight [13].

The integration of efficient solid-state thermoelectric microconverters with microelectronics is desirable for local cooling and thermoelectric microgeneration because they can be used to stabilize the temperature of devices, decrease noise levels, and increase operation speed. Moreover, microthermoelectric generators can be used in a lot of small low-power devices such as hearing aids or wristwatches. This has been shown by Seiko and Citizen with their commercialized thermoelectrically driven low-power wristwatches [14]. Despite the range of exciting applications, only few approaches to manufacture thermoelectric devices with small dimensions have been reported up to now [14]-[17].

Due to silicon fabrication compatibility, polycrystalline SiGe alloys and polycrystalline $\mathrm{Si}$ are commonly used in thermopile applications. Their use in microcoolers has been attempted, but the performance is very low compared with that of tellurium compounds, which have been used for many years in conventional large-area cooling devices [18]. Tellurium compounds (n-type bismuth telluride $\mathrm{Bi}_{2} \mathrm{Te}_{3}$ and p-type antimony telluride $\mathrm{Sb}_{2} \mathrm{Te}_{3}$ ) are well-established room-temperature thermoelectric materials and are widely employed by the industry in conventional thermoelectric generators and coolers. Different deposition techniques were tried to obtain thin films of these materials. Thermal coevaporation, cosputtering, electrochemical deposition, metal-organic chemical vapor deposition, and flash evaporation are some examples. The fabrication of thermoelectric energy scavenging microsystems with tellurium alloys allows powering small electronic devices (up to units of milliwatts) under temperature gradients below $10^{\circ} \mathrm{C}$.

The performance of thermoelectric devices depends on the figure of merit $(Z T)$ of the material [19], which is given by

$$
Z T=\frac{\alpha^{2}}{\rho \lambda} T
$$

where $\alpha$ is the Seebeck coefficient, $\rho$ is the electrical resistivity, $\lambda$ is the thermal conductivity, and $T$ is the temperature.

In this paper, films with high figure of merit were deposited by coevaporation, and low-cost wet-etching techniques were used to pattern thermoelectric microconverters. These microconverters were used in thermoelectric energy scavenging systems to work as energy sources for low-powered devices such as microsensor systems, where a temperature difference exists between the two surfaces of the microgenerator. (a)

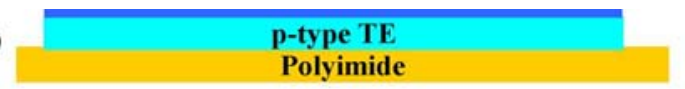

(b)

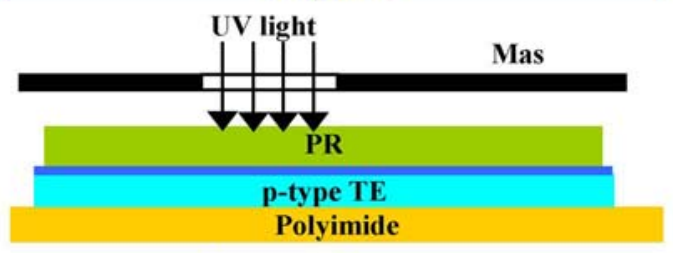

(c)

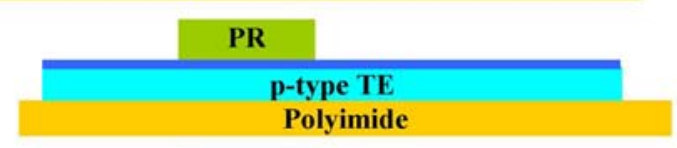

(d)

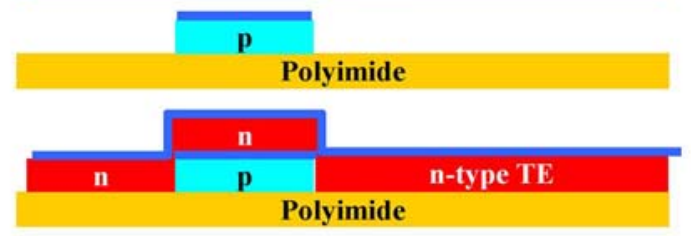

(e)

Polyimide

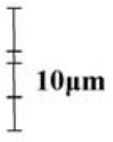

(f)

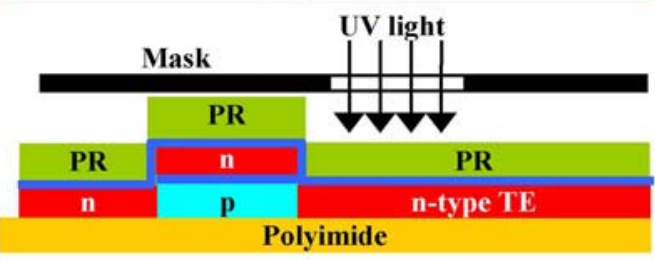

(g)

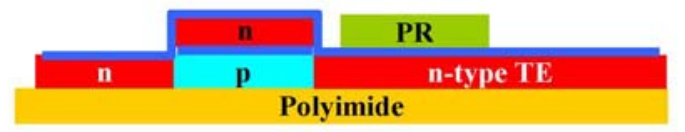

(h)

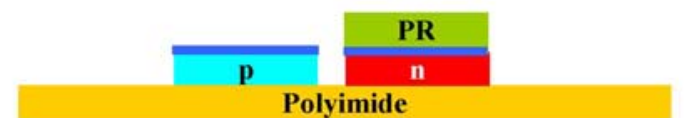

(i)

(j)

(k)

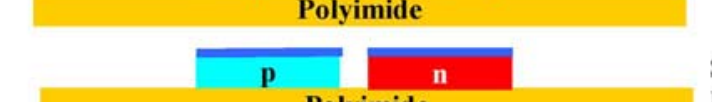

.

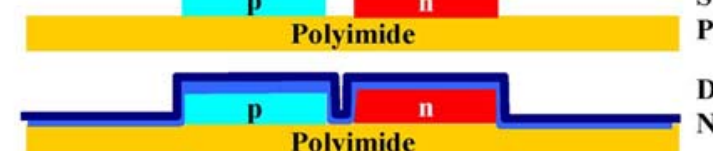

PR

Deposit

$\mathbf{N i}+\mathbf{A l}$

(1)

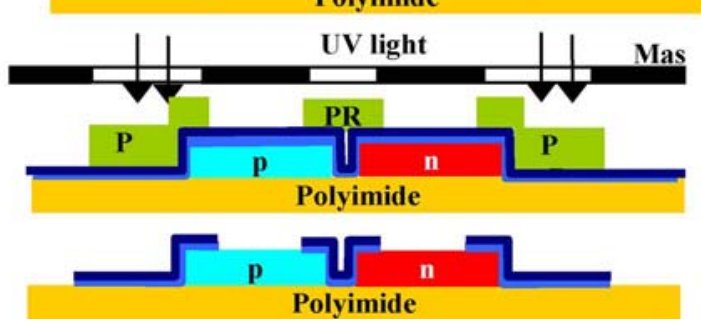

Fig. 2. Fabrication steps of the thermoelectric microconverter.

\section{FABRICATION}

Two different approaches can be used for on-chip integration of thermoelectric devices: transversal (cross-plane) and lateral (in-plane), depending on the direction in which the energy is removed, relative to the surface of the device. In this paper, lateral heat flow is addressed due to its easier fabrication process and compliance with planar technology. Fig. 2 shows the fabrication process of thermoelectric microconverters. The p-type $\mathrm{Sb}_{2} \mathrm{Te}_{3}$ film is deposited by thermal coevaporation, followed by a thin layer $(100 \mathrm{~nm})$ of nickel (a). The use of thin layers of nickel helps one to avoid diffusion of the thermoelectric material into the next deposited layers. Photoresist is spun, and p-type elements are patterned by photolithography 


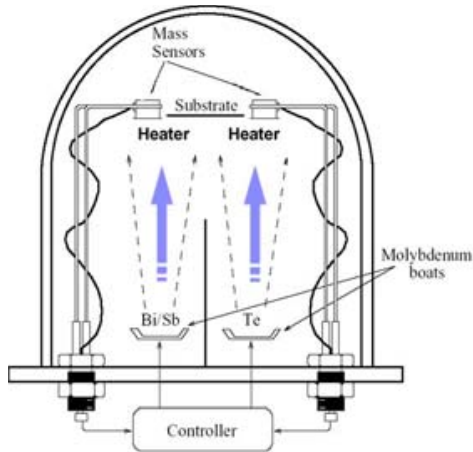

(a)

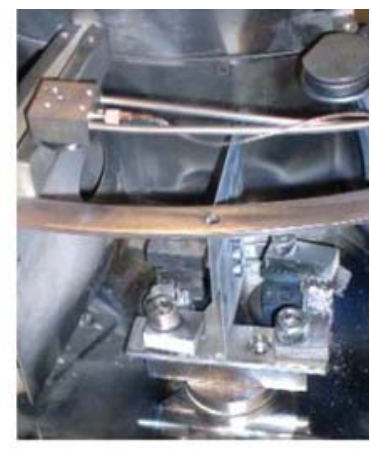

(b)
Fig. 3. (a) Coevaporation system. (b) Boats and mass sensors placed inside the codeposition chamber.

(b)-(c). Nickel is etched in a chromium etchant (Transene 1020), a thermoelectric film is patterned by wet etching in HNO3: $\mathrm{HCl}(\mathrm{d})$, and the photoresist is removed. The n-type film is then deposited by coevaporation, followed by a 100-nm nickel layer (e). The photoresist is applied and patterned by photolithography for n-type element definition (f)-(g). Nickel is etched in a chromium etchant (Transene 1020), the n-type film is etched in HNO3 (h), and the photoresist is removed (i). Contacts are deposited, starting with a 100-nm layer of nickel, followed by $1 \mu \mathrm{m}$ of aluminum (j). The photoresist is spun, and contacts are patterned by photolithography $(\mathrm{k})$. Nickel is etched in a chromium etchant (Transene 1020), while aluminum is etched in a standard aluminum etchant (Transene type A). The photoresist is removed (1). A protective layer of $\mathrm{Si}_{3} \mathrm{~N}_{4}$ can also be deposited by low-temperature hot-wire chemical vapor deposition (HW-CVD) and patterned if required, depending on the application.

\section{A. Deposition of Thin Films}

Thermoelectric films were fabricated by the thermal coevaporation technique (Fig. 3) in a high-vacuum chamber (with a base pressure of $\sim 1 \times 10^{-6}$ torr). Two large molybdenum boats (baffled boxes with a volume of $4 \mathrm{~cm}^{3}$ ) are used at the same time, i.e., one for each of the elementary materials required to produce the desired compound.

The power applied to each boat is controlled independently, using two computed proportional-integral-derivative controllers [20] to maintain the deposition rate at user-defined constant values, during the deposition process. Two thickness monitors (quartz crystal oscillators) are carefully placed inside the chamber in such a way that each of them receives the material only from the boat that it is monitoring. A metal sheet is placed between the two boats to prevent the mixing of both materials at the quartz crystal sensors. Substrates are heated to the temperature set point $\left(T_{\text {sub }}\right)$ in the range of $150{ }^{\circ} \mathrm{C}-270{ }^{\circ} \mathrm{C}$.

\section{B. Patterning}

Thermoelectric $\mathrm{Bi}_{2} \mathrm{Te}_{3}$ and $\mathrm{Sb}_{2} \mathrm{Te}_{3}$ thin films (1 $\mu \mathrm{m}$ thick) were deposited on the Kapton substrate. Transene's PKP negative photoresist was applied on the surface, and test structures were patterned by wet etching in the $\mathrm{HNO}_{3}: \mathrm{HCl}: \mathrm{H}_{2} \mathrm{O}$

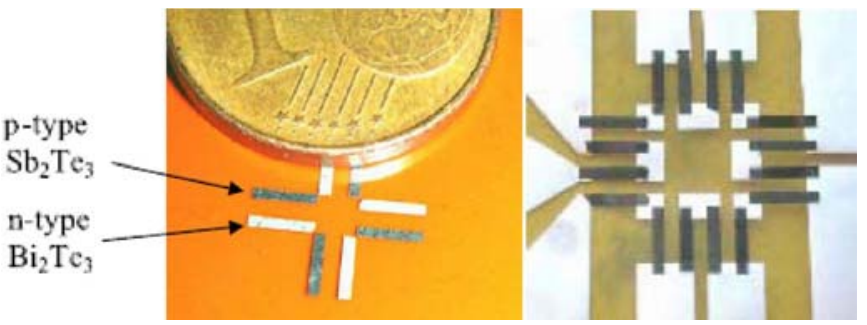

Fig. 4. (Left) Photograph of $\mathrm{n}$ - and $\mathrm{p}$-type elements before the deposition of the top contacts. (Right) Photograph of a thermoelectric microconverter with eight pairs of thermoelectric elements, fabricated with the bottom contacts.

TABLE I

Properties of the Selected SAMPles OF $\mathrm{Bi}_{2} \mathrm{Te}_{3}$ Films

\begin{tabular}{|c|c|c|c|c|}
\hline Film & $\alpha\left[\mu \mathbf{V K}^{-1}\right]$ & $\rho[\mu \Omega . \mathrm{m}]$ & $P F \times 10^{-3}\left[\mathrm{WK}^{-1} \mathrm{~m}^{-2}\right]$ & $Z T @ 300 \mathrm{~K}$ \\
\hline$\# 1$ & -74 & 5.7 & 0.96 & 0.19 \\
\hline$\# 2$ & -180 & 16.6 & 1.95 & 0.4 \\
\hline \#3 & -156 & 11.3 & 2.16 & 0.43 \\
\hline$\# 4$ & -152 & 13.4 & 1.72 & 0.34 \\
\hline$\# 5$ & -248 & 12.6 & 4.87 & 0.97 \\
\hline \#6 & -220 & 10.6 & 4.57 & 0.91 \\
\hline
\end{tabular}

TABLE II

Properties of THe Selected SAMPLES OF $\mathrm{Sb}_{2} \mathrm{Te}_{3}$ Films

\begin{tabular}{|c|c|c|c|c|}
\hline Sample & $\alpha\left[\mu \mathbf{V K}^{-1}\right]$ & $\rho[\mu \Omega . \mathrm{m}]$ & $\boldsymbol{P F \times 1 0 ^ { - 3 }}\left[\mathbf{W K}^{-\mathbf{1}} \mathbf{m}^{-\mathbf{2}}\right]$ & $\boldsymbol{Z T} @ \mathbf{3 0 0} \mathbf{K}$ \\
\hline$\# 7$ & 91 & 7.6 & 1.09 & 0.22 \\
\hline$\# 8$ & 140 & 14.0 & 1.40 & 0.28 \\
\hline$\# 9$ & 156 & 9.2 & 2.66 & 0.53 \\
\hline$\# 10$ & 188 & 12.6 & 2.81 & 0.56 \\
\hline
\end{tabular}

etchant (pure $\mathrm{HNO}_{3}$ and $37 \% \mathrm{HCl}$ diluted in water). Fig. 4 shows a planar thermoelectric microconverter fabricated on top of a $25-\mu \mathrm{m}$-thick Kapton foil. As shown in that figure, the contacts can be deposited on the top or bottom of the thermoelectric films. Because $\mathrm{Bi}_{2} \mathrm{Te}_{3}$ and $\mathrm{Sb}_{2} \mathrm{Te}_{3}$ adhesion is higher on polyimide (Kapton) films than that on nickel metal pads, the use of the top-contact process (as shown in Fig. 2) avoids the need of depositing additional layers to promote the adhesion of thermoelectric films.

\section{EXPERIMENTAL RESULTS}

The in-plane film electrical resistance was measured using the conventional four-probe van der Pauw method at room temperature. The thermal conductivity was measured using the method proposed by Völklein [21]. The values of 1.3 and $1.8 \mathrm{~W} \cdot \mathrm{m}^{-1} \cdot \mathrm{K}^{-1}$ were obtained for the $\mathrm{Bi}_{2} \mathrm{Te}_{3}$ and $\mathrm{Sb}_{2} \mathrm{Te}_{3}$ films, respectively. The measurements of the Seebeck coefficient were made by connecting one side of the film to a fixed temperature (heated metal block) and the other side to a heat sink at room temperature. Tables I and II show the results of these measurements in the selected samples of $\mathrm{Bi}_{2} \mathrm{Te}_{3}$ and $\mathrm{Sb}_{2} \mathrm{Te}_{3}$ films.

In both tables, the first column lists the number of the selected sample, the second column contains the values of 
Seebeck coefficient $\alpha$, and the third column has the electrical resistivity $\rho$ of the films. The fourth column lists the $P F$ for the selected samples of $\mathrm{Bi}_{2} \mathrm{Te}_{3}$ and $\mathrm{Sb}_{2} \mathrm{Te}_{3}$, whose values were calculated using the following:

$$
P F=\alpha^{2} / \rho\left[\mathrm{W} \cdot \mathrm{K}^{-1} \cdot \mathrm{m}^{-2}\right] .
$$

It must be noted that, behind the figure of merit $(Z T)$, power factor $P F$ (in watts per kelvin per square meter) is perhaps the most important value in a thermoelectric converter and gives the electric power versus the area where the heat flow happens, plus the temperature gradient between the hot and cold sides. Moreover, Tables I and II present the corresponding figures of merit $(Z T)$, which were calculated from (1).

In-plane electrical resistivity, carrier concentration, and Hall mobility were measured at room temperature using the conventional four-probe van der Pauw geometry. A dc magnetic field of $80 \mathrm{mT}$ was applied for Hall measurements. Seebeck coefficient $\alpha$ was measured by connecting one side of the film to a heated metal block at a fixed temperature and the other side to a heat sink kept at room temperature, with a temperature difference between both sides below $10{ }^{\circ} \mathrm{C}$. A spot of $\approx 5 \mathrm{~mm} \times 5 \mathrm{~mm}$ is considered for electrical properties. Thermal conductivity was measured using the technique developed in [21]. The measurements made in the selected samples showed an absolute value of the Seebeck coefficient in the range of $150-250 \mu \mathrm{V} \cdot \mathrm{K}^{-1}$ and an in-plane electrical resistivity of $7-15 \mu \Omega \cdot \mathrm{m}$.

In a conventional thermoelectric element, the effect of electrical contact on the interface with the metal is usually not taken into consideration, which is acceptable, as the contact between the two conductors is significantly smaller than the electrical resistance of the thermoelements [22]. The influence of electrical contact resistance cannot be disregarded in on-chip integrated thermoelectric devices due to the size of the contact relative to the length of the thermoelectric converter [23]. For comparison, the contact area of a conventional thermoelement is on the order of $1 \times 1 \mathrm{~mm}^{2}$, while that of the integrated thermoelement is on the order of $10 \times 10 \mu \mathrm{m}^{2}$ (i.e., an area reduction of $10^{4}$ ). Electrical contacts are made at both the hot and cold junctions of the device. Because the hot junctions are considered to be in direct contact with the ambient, the Joule heat generated in these junctions is absorbed locally and does not affect the maximum temperature difference. However, the Joule heat generated due to the electrical contact at the cold junctions has to travel through the entire length of the device to reach the ambient [22]. The contact resistance between the thermoelectric material and the metallic contact was measured with the help of the transmission-line model method [24]. The measurements shown for the $\mathrm{n}$ - and $\mathrm{p}$-type materials are maximum contact resistivities of $2 \times 10^{-7}$ and $5 \times 10^{-7} \Omega \cdot \mathrm{m}^{2}$, respectively.

The measurements also shown for the $\mathrm{Bi}_{2} \mathrm{Te}_{3}$ and $\mathrm{Sb}_{2} \mathrm{Te}_{3}$ films are figures of merit $(Z T)$ at room temperature of 0.84 and 0.5 and power factors $P F \times 10^{-3}\left[\mathrm{~W} \cdot \mathrm{K}^{-1} \cdot \mathrm{m}^{-2}\right]$ of 4.87 and 2.81 , respectively.

Using thermoelectric converters for human-body energy harvesting requires the generator thermal resistance to be matched

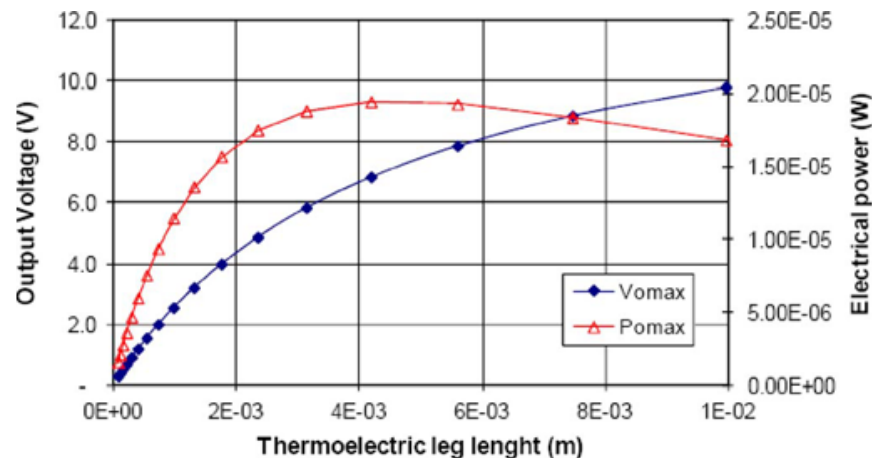

Fig. 5. Open-circuit output voltage and power of a $1-\mathrm{cm}^{2} \mathrm{Bi}_{2} \mathrm{Te}_{3}-\mathrm{Sb}_{2} \mathrm{Te}_{3}$ thermoelectric generator, plotted as a function of the length of the column.

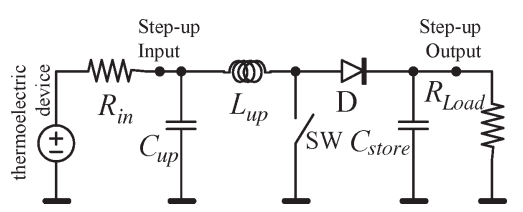

Fig. 6. Schematic of a simple step-up circuit.

to the human-body and heat-sink thermal loads. The maximum voltage output is obtained when the thermal resistance of the thermoelectric legs is equal to the heat-sink and human-body thermal resistances. A thermal resistance of $200 \mathrm{~K} \cdot \mathrm{W}^{-1}$. $\mathrm{cm}^{-2}$ is desirable in the thermoelectric microconverter. Because each thermoelectric junction of $\mathrm{Bi}_{2} \mathrm{Te}_{3}-\mathrm{Sb}_{2} \mathrm{Te}_{3}$ can deliver an output voltage of $300 \mu \mathrm{V} \cdot \mathrm{K}^{-1}$, more than 4000 junctions are necessary to obtain an output voltage (without load) of $10 \mathrm{~V}$ under a temperature difference of $10{ }^{\circ} \mathrm{C}$. Fig. 5 shows the open-circuit voltage and power that can be obtained in a 1- $\mathrm{cm}^{2} \mathrm{Bi}_{2} \mathrm{Te}_{3}-\mathrm{Sb}_{2} \mathrm{Te}_{3}$ thermoelectric generator, when the length of the columns is up to $10 \mathrm{~mm}$. The maximum power output is obtained with a column length of $4 \mathrm{~mm}$.

\section{AppliCATiOnS}

Energy-harvested wireless sensors must be powered in a peak basis because a temperature gradient could not be present always; thus, energy must be stored in a capacitor (storage capacitor) for later use by the electronic system to be powered [9] or in a rechargeable microbattery of Li-ion type (integrated in the system) [25]. In both cases, an ultralow power electronics performs dc-dc rectification with a variable conversion factor. Fig. 6 shows a simple step-up converter. The step-up conversion is made with the help of capacitor $C_{\mathrm{up}}$ and inductor $L_{\mathrm{up}}$. The current at the output of the thermoelectric microdevice charges this capacitor, and then, the switch (SW) is systematically closed and open with a high frequency. However, it remains closed during a very short time in order to reduce the losses. In order to meet this requirement, the command signal must have a very low duty cycle to avoid the overdischarge of capacitor $C_{\mathrm{up}}$. When $\mathrm{SW}$ opens, the stored energy in inductor $L_{\text {up }}$ forces capacitor $C_{\text {up }}$ to discharge through diode $D$, e.g., a dc rectification is present. Then, the current charges highcharge-capacity capacitor $C_{\text {store }}$, which further connects to a dc regulator. 


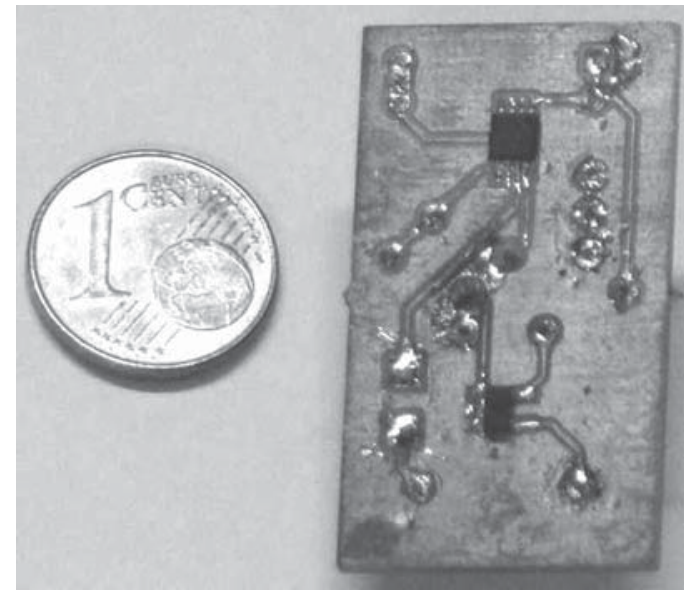

Fig. 7. Photograph of the CP, followed by the step-up.

Because the target goals for the proposed thermoelectric microconverter are biomedical applications, a more compact solution for the power circuit is mandatory. Using discrete but still compact solution, the first circuit prototype was mounted to make the step-up conversion [5]. Fig. 7 shows such a circuit, which is composed by a charge pump (CP), followed by a $\mathrm{dc}-\mathrm{dc}$ step-up converter. When the voltage at the output of the thermoelectric device rises above a certain value (in this circuit, the chosen voltage was $300 \mathrm{mV}$ ), the $\mathrm{CP}$ activates an output pin that will activate the dc-dc step-up circuit. In this situation, a short circuit is established between the thermoelectric device and the input of the dc-dc step-up. Then, the step-up puts a regulated IC-compatible voltage to supply the electronics. The measurements made in this prototype showed that, when the voltage at the output of the thermoelectric microdevice crosses above $300 \mathrm{mV}$, then the output of CP will enable the step-up, which will increase the voltage up to $3 \mathrm{~V}$.

\section{A. Wireless EEG as a Biomedical Application}

Temperatures ranging from $27{ }^{\circ} \mathrm{C}$ to $36{ }^{\circ} \mathrm{C}$ can be found in different parts of a body. However, higher temperature gradient in relation to the ambient is found in the forehead and nose. Standard wireless electroencephalograms (EEGs) use a brain cap with wires running from the electrode position to a bulky central unity (amplification, signal filtering, and analog-todigital conversion) [26]. A more interesting solution is to use compact wireless EEG modules, where the electronics, antenna, and each electrode are mounted together. The power supply of such modules is obtained locally from the thermoelectric generator. This solution allows one to integrate additional electronics (amplification, filtering, and high-resolution digital conversion) for local signal processing inside these small-size individual wireless EEG modules.

It is possible to use either bipolar or unipolar electrodes in the EEG measurement. In the first method, the potential difference between a pair of electrodes is measured, but an electrode placed in a reference position is needed for all modules. In the second method, the potential of each electrode is compared, either to a neutral (the reference) electrode or to the average of all electrodes.
Fig. 8 shows the full block diagram of the wireless EEG module and the thermoelectric module, where the electrode connected to an amplifier can be seen, followed by an analogto-digital converter (ADC). In order to meet the EEG specifications, the amplifier was designed to have enough gain to amplify signals with amplitudes of only $70 \mu \mathrm{V}$. The ADC must have at least a resolution of $22 \mathrm{~b}$ and a minimum sampling frequency of $2000 \mathrm{~Hz}$.

Plug-and-play wireless EEG modules were previously demonstrated by the authors [27]. In this paper, a thermoelectric generator with $\mathrm{CP}$ and $\mathrm{dc}-\mathrm{dc}$ conversion is proposed. Fig. 9 shows an artist impression of the thermoelectric energy scavenging system and a wireless EEG module, both attached to a cap (the zoomed-in part in the figure). The temperature gradient between the forehead and the environment will generate energy in the thermoelectric microdevice to supply the modules.

\section{CONCLUSion AND Future Work}

This paper has presented a thermoelectric microconverter to supply low-power electronics, where the power consumption ranges from hundredths of microwatts to a few milliwatts. The microconverter is made of thermoelectric structures based on thin films of n-type bismuth telluride $\left(\mathrm{Bi}_{2} \mathrm{Te}_{3}\right)$ and p-type antimony telluride $\left(\mathrm{Sb}_{2} \mathrm{Te}_{3}\right)$. The measurements have shown that the deposited films present thermoelectric properties that are comparable to those reported for the same materials in bulk form, as is the case of the materials used in conventional macroscale Peltier modules. The absolute values of the Seebeck coefficient are in the $150-250-\mu \mathrm{V} \cdot \mathrm{K}^{-1}$ range, and the inplane electrical resistivity is in the $7-15-\mu \Omega \cdot \mathrm{m}$ range. The measurements also shown for the $\mathrm{Bi}_{2} \mathrm{Te}_{3}$ and $\mathrm{Sb}_{2} \mathrm{Te}_{3}$ films are the figures of merit $(Z T)$ at room temperature of 0.84 and 0.5 and power factors $P F \times 10^{-3}\left[\mathrm{~W} \cdot \mathrm{K}^{-1} \mathrm{~m}^{-2}\right]$ of 4.87 and 2.81 , respectively. The proposed converter uses the Seebeck effect for doing the thermoelectric conversion, using microsystem techniques and suitable to be integrated with electronics. The target applications for this thermoelectric microconverter include the wireless EEG and use the temperature gradient between the ambient and the forehead to supply the wireless modules.

Future research will pursue the operation from lowtemperature gradients (a minimum temperature difference of $3{ }^{\circ} \mathrm{C}$ between the ambient and the thermosource must provide an IC-compatible voltage). Today, the best commercial thermoelectric modules (made of $\mathrm{Bi}, \mathrm{Sb}$, and $\mathrm{Te}$ compounds) have a $Z T$ of one, despite the many approaches to find compounds with high performance. In conventional 3-D crystalline systems, it is difficult to control each of the following interrelated factors to improve $Z T$ [28]: Seebeck voltage per unit of temperature, electrical conductivity, and thermal conductivity. This means that an increase of Seebeck voltage per unit temperature usually results in a decrease of electrical conductivity. Moreover, a decrease of electrical conductivity leads to a decrease of electronic contribution to thermal conductivity, following the Wiedemann-Franz law. However, if the dimensionality of the material is decreased, the new variable of length scale becomes available for the control of material properties due to the differences in the density of electronic states. A recent 


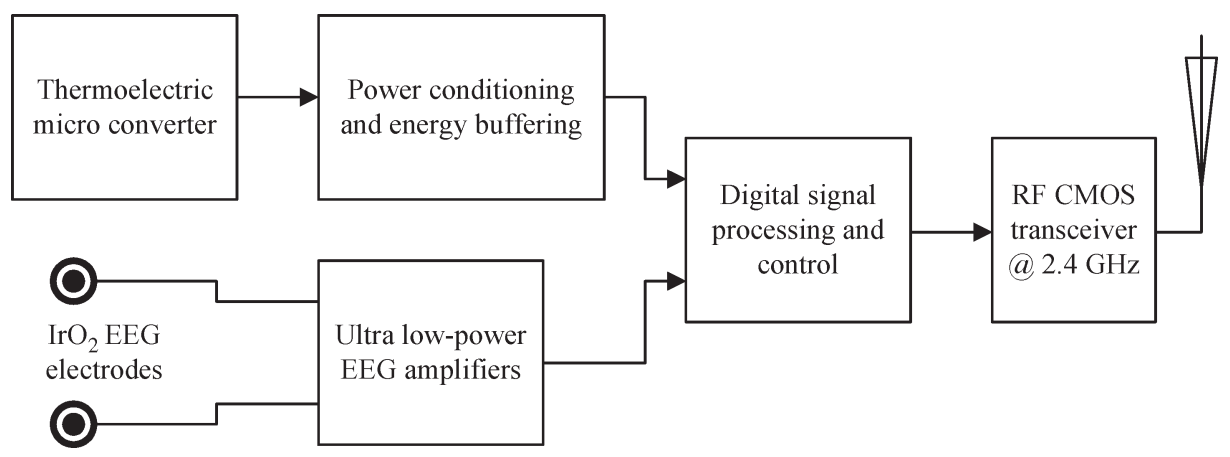

Fig. 8. System architecture behind the wireless autonomous EEG system powered by the body heat recovered with the proposed thermoelectric microconverter.

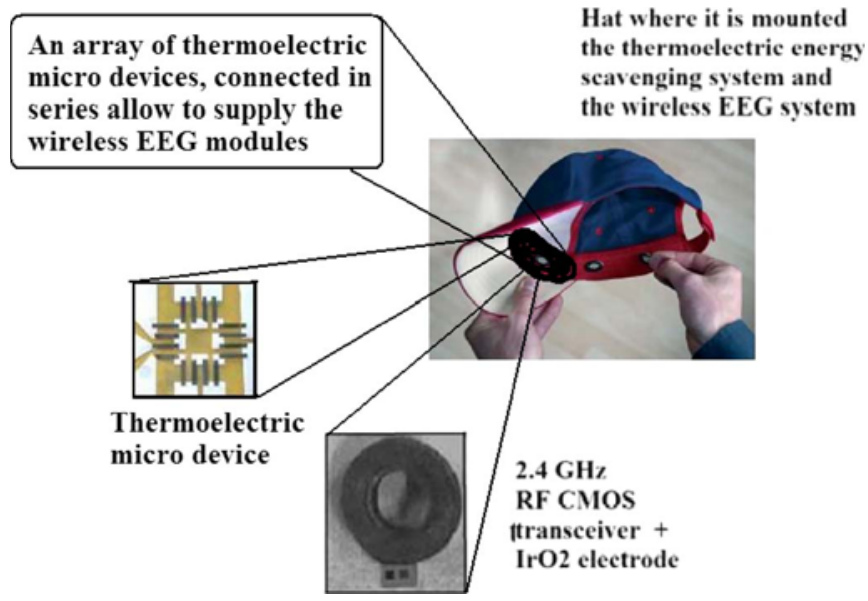

Fig. 9. Sketch of the thermoelectric energy scavenging system with a wireless EEG module.

work with BiSbTe superlattices demonstrated an enhancement in $Z T$ to about 2.4 [29] and 1.4 [30]. Thus, thermoelectric microdevices with high figures of merit, based on superlattices, are the key to generate power from low-temperature gradients for biomedical applications.

In future research, both HW-CVD and sputtering deposition systems will be used to build nanostructured superlattices. Both techniques allow a reduced substrate temperature, which is essential to reduce interdiffusion of layers. It is also possible to deposit amorphous, nanocrystalline, or microcrystalline films.

\section{REFERENCES}

[1] J. M. Carrasco, L. G. Franquelo, J. T. Bialasiewicz, E. Galvan, R. C. Portillo-Guisado, M. A. M. Prats, J. I. Leon, and N. Moreno-Alfonso, "Power-electronic systems for the grid integration of renewable energy sources: A survey," IEEE Trans. Ind. Electron., vol. 53, no. 4, pp. 1002-1016, Jun. 2006.

[2] J. Schonberger, R. Duke, and S. D. Round, "DC-bus signaling: A distributed control strategy for a hybrid renewable nanogrid," IEEE Trans. Ind. Electron., vol. 53, no. 5, pp. 1453-1460, Oct. 2006.

[3] R. Way, W. Wang, and C. Lin, "High-performance stand-alone photovoltaic generation system," IEEE Trans. Ind. Electron., vol. 55, no. 1, pp. 240-250, Jan. 2008.

[4] J. Colomer-Ferrarons, P. Miribel-Català, A. Saiz-Vela, M. Puig-Vidal, and J. Samitier, "Power-conditioning circuitry for a self-powered system based on micro PZT generators in a $0.13-\mu \mathrm{m}$ low-voltage low-power technology," IEEE Trans. Ind. Electron., vol. 55, no. 9, pp. 3249-3257, Sep. 2008

[5] L. Mateu, C. Codrea, N. Lucas, M. Pollak, and P. Spies, "Human body energy harvesting thermogenerator for sensing applications," in Proc. Int. Conf. Sens. Technol. Appl., Valencia, Spain, Oct. 2007, pp. 366-372.
[6] L. Collins, "Harvest for the world," IEEE Power Eng. J., vol. 20, no. 1, pp. 34-37, Feb./Mar. 2006.

[7] J. Bouchaud and R. Dixon, "Micro-energy harvesters: Overview, applications and markets," MSTnews: Int. Newslett. Micro-Nano Integr., no. 1/08, pp. 18-19, Feb. 2008.

[8] D. Dondi, A. Bertaccini, D. Brunelli, L. Larcher, and L. Benini, "Modeling and optimization of a solar energy harvester system for self-powered wireless sensor networks," IEEE Trans. Ind. Electron., vol. 55, no. 7, pp. 2759-2766, Jul. 2008.

[9] L. Mateu and F. Moll, "Appropriate charge control of the storage capacitor in a piezoelectric energy harvesting device for discontinuous load operation," Sens. Actuators A, Phys., vol. 132, no. 1, pp. 302-310, Nov. 2006.

[10] J. Liu and J. Yao, "Wireless RF identification system based on SAW," IEEE Trans. Ind. Electron., vol. 55, no. 2, pp. 958-961, Feb. 2008.

[11] C. Vining, "Semiconductors are cool," Nature, vol. 413, no. 6856, pp. 577-578, Oct. 11, 2001.

[12] L. Bell, "Cooling, heating, generating power, and recovering waste heat with thermoelectric systems," Science, vol. 321, no. 5895, pp. 1457-1461, Sep. 12, 2008.

[13] W. Qu, M. Plötner, and W. Fischer, "Microfabrication of thermoelectric generators on flexible foil substrates as a power source for autonomous microsystems," J. Micromech. Microeng., vol. 11, no. 2, pp. 146-152, Mar. 2001.

[14] H. Böttner, J. Nernus, A. Gavrikov, G. Kühner, M. Jägle, C. Künzel, D. Eberhard, G. Plescher, A. Schubert, and K. Schlereth, "New thermoelectric components using microsystem technologies," J. Microelectromech. Syst., vol. 13, no. 3, pp. 414-420, Jun. 2004.

[15] L. da Silva and M. Kaviany, "Fabrication and measured performance of a first-generation microthermoelectric cooler," J. Microelectromech. Syst., vol. 14, no. 5, pp. 1110-1117, Oct. 2005.

[16] G. J. Snyder, J. R. Lim, C. Huang, and J. Fleurial, "Thermoelectric microdevice fabricated by a MEMS-like electrochemical process," Nat. Mater, vol. 2, no. 8, pp. 528-531, Aug. 2003.

[17] H. Böttner, "Micropelt miniaturized thermoelectric devices: Small size, high cooling power densities, short response time," in Proc. 24th ICT, Clemson, SC, Jun. 2005, pp. 1-8.

[18] D. D. L. Wijngaards, S. H. Kong, M. Bartek, and R. F. Wolffenbuttel, "Design and fabrication of on-chip integrated polySiGe and polySi Peltier devices," Sens. Actuators A, Phys., vol. 85, no. 1-3, pp. 316-323, Aug. 2000.

[19] G. Min and D. M. Rowe, "Ring-structured thermoelectric module," Semicond. Sci. Technol., vol. 22, no. 8, pp. 880-883, Aug. 2007.

[20] Y. F. Chan, M. Moallem, and W. Wang, "Design and implementation of modular FPGA-based PID controllers," IEEE Trans. Ind. Electron., vol. 54, no. 4, pp. 1898-1906, Aug. 2007.

[21] F. Völklein, "Characterization of the thermal properties of bulk and thin-film materials by using diagnostic microstructures," in Proc. Symp. Microtechnol. Metrol. Metrol. Microsyst., Delft, The Netherlands, Aug. 2000, pp. 91-107.

[22] D. D. L. Wijngaards and R. F. Wolffenbuttel, "Thermo-electric characterization of APCVD polySi ${ }_{0.7} \mathrm{Se}_{0.3}$ for IC-compatible fabrication of integrated lateral Peltier elements," IEEE Trans. Electron Devices, vol. 52, no. 5, pp. 1014-1025, May 2005.

[23] D. D. L. Wijngaards and R. F. Wolffenbuttel, "Characterization and modeling of planar on-chip integrated Peltier elements for highly-localized thermal stabilization and cooling," in Proc. 18th SemiTherm, San Jose, CA, Mar. 2002, pp. 105-112. 
[24] G. K. Reeves and H. B. Harrison, "Obtaining the specific contact resistance from transmission line model measurements," IEEE Electron Device Lett., vol. EDL-3, no. 5, pp. 111-113, May 1982.

[25] M. A. Alahmad and H. L. Hess, "Evaluation and analysis of a new solidstate rechargeable microscale lithium battery," IEEE Trans. Ind. Electron., vol. 55, no. 9, pp. 3391-3401, Sep. 2008.

[26] IMEC press releases, ambulatory EEG, human ++ EU project, pp. $1-2,2003$

[27] J. P. Carmo, N. S. Dias, H. R. Silva, P. M. Mendes, C. Couto, and J. H. Correia, "A 2.4-GHz low-power/low-voltage wireless plug-and-play module for EEG applications," IEEE Sensors J., vol. 7, no. 11, pp. 15241531, Nov. 2007.

[28] D. Hicks and M. S. Dresselhaus, "Effect of quantum-well structures on the thermoelectric figure of merit," Phys. Rev. B, Condens. Matter, vol. 47, no. 19, pp. 12727-12 731, May 15, 1993.

[29] R. Venkatasubramanian, E. Siivola, T. Colpitts, and B. O'Quinn, "Thinfilm thermoelectric devices with high room-temperature figures of merit," Nature, vol. 413, no. 6856, pp. 597-602, Oct. 11, 2001.

[30] H. Böttner, G. Chen, and R. Venkatasubramanian, "Aspects of thin-film superlattice thermoelectric materials, devices, and applications," MRS Bull., vol. 31, no. 3, pp. 211-217, Mar. 2006.

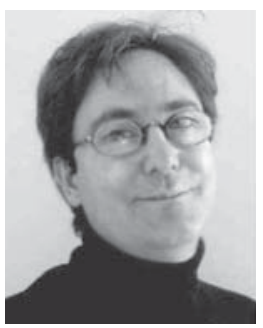

João Paulo Carmo (S'02-M'08) was born in Maia, Portugal, in 1970. He received the B.S. and M.Sc. degrees in electrical engineering from the University of Porto, Porto, Portugal, in 1993 and 2002, respectively, and the $\mathrm{Ph} . \mathrm{D}$. degree in industrial electronics from the University of Minho, Guimarães, Portugal, in 2007. His Ph.D. thesis was on RF transceivers for integration in microsystems to be used in wireless sensor network applications.

Since 2008, he has been an Assistant Researcher at the Algoritmi Center, University of Minho, where he is also currently with the Department of Industrial Electronics. $\mathrm{He}$ is involved in research on micro-/nanofabrication technologies for mixed-mode/RF systems, solid-state integrated sensors, microactuators, and micro-/nanodevices for use in wireless and biomedical applications.

Dr. Carmo is a member of the IEEE Industrial Electronics Society.

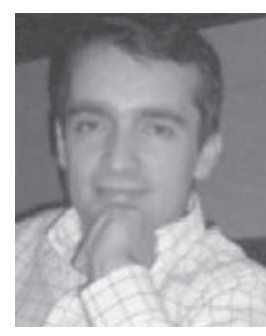

Luis Miguel Gonçalves received the B.S. and M.Sc. degrees in industrial electronics engineering and the Ph.D. degree from the University of Minho, Guimarães, Portugal, in 1993 and 1999, respectively. His Ph.D. thesis was on thermoelectric microsystems for on-chip cooling and energy harvesting.

From 1993 to 2002, he researched embedded systems and electronics at the Institute for Development and Technological Innovation of Minho, Braga, Portugal, an institute that was built through a joint initiative of the University of Minho and industry. Since 2002, he has been a Lecturer in the Department of Industrial Electronics, University of Minho. There, he started a new laboratory on thermoelectric thin-film deposition, characterization, and patterning in collaboration with the Department of Physics. His professional interests are thin-film devices for thermoelectric energy applications, micromachining and microfabrication technology, and solid-state integrated microsystems.

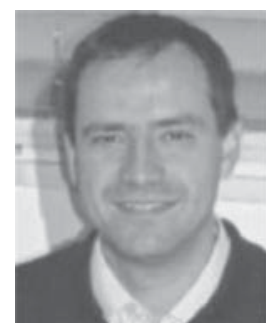

José Higino Correia (S'96-M'00) received the B.S. degree in physical engineering from the University of Coimbra, Coimbra, Portugal, in 1990, and the $\mathrm{Ph} . \mathrm{D}$. degree from the Electronic Instrumentation Laboratory, Delft University of Technology, Delft, The Netherlands, in 1999, working in the field of microsystems for optical spectral analysis.

$\mathrm{He}$ is currently a Full Professor in the Department of Industrial Electronics, University of Minho, Guimarães, Portugal. His professional interests are micromachining and microfabrication technology for mixed-mode systems, solid-state integrated sensors, microactuators, and microsystems.

Prof. Correia is a member of the IEEE Industrial Electronics Society. $\mathrm{He}$ was the General Chairman of Eurosensors 2003 and Micromechanics and Microengineering Europe 2007 held in Guimarães. 